\title{
The Challenges of Teaching and Learning English Literature in L2 Context: The Case of Junior Secondary Schools in Botswana
}

\author{
Deborah Adeninhun Adeyemi
}

\begin{abstract}
Various Botswana policy documents (Republic of Botswana, 1977, 1994, 2002) and Vision 2016 (1997) have advocated for an enlightened and well-informed society and the provision of a ten-year basic education as a fundamental human right of her citizens. It is against this background that this paper discusses the importance of English Literature in the Junior Secondary School (JSS) curriculum and examines the challenges faced by teachers and students in the teaching/learning process that can hamper the achievement of the country's educational and social goals. Two Form One classes were chosen in two schools in Gaborone, the capital of Botswana, for this study. The 35 students in each of the two classes (totaling 70 students) and their 2 teachers were used in the study by adopting simple qualitative and quantitative descriptions. The study showed that the major difficulties faced by the teachers include lack of interest/enthusiasm for learning the subject by the students, as well as their lack of basic background in English, among others. Other problems on the part of the students include difficulty in understanding and difficult vocabulary/language in texts. As a result, pertinent recommendations were made for improved teacher practices and strategies.
\end{abstract}

\section{Introduction}

In Botswana, the provision of quality basic education is viewed as a fundamental human right. Basic education in this context aims at fostering intellectual growth and creativity, enabling every citizen to achieve their full potential and prepare them for life in the 21st Century-The Curriculum Blueprint (Republic of Botswana, 2002).

Various policy documents, such as the National Commission on Education (Republic of Botswana, 1977), Revised National Policy on Education (RNPE; Republic of Botswana, 1994) and Vision 2016 (Republic of Botswana, 1997) stress the building of a nation enviable to the global community through the education of its citizens. It is the view that literature education is important to the achievement of the nation's educational and social goals. To this end, the study of literature in both English and Setswana (the national language) become useful tools in the achievement of the outlined goals. 


\section{Background to the Study}

English literature is used at the junior secondary level in Botswana to teach literacy in the English language. A part of the junior secondary English syllabus states that the study of literature will enable pupils gain further practice in the key areas of the four language skills of listening, speaking, reading and writing (Republic of Botswana, 2008), consolidating these skills in interesting and communicative ways to enrich learners' day-to-day language learning and use. It is also hoped that the study of literature at this level will encourage learners to develop a culture of reading which will help them have access to information on a wide variety of topics, and thereby become informed and educated as stated in Vision 2016.

It is important to emphasize that the teaching and learning of literature at the junior secondary level through works of fiction, drama and poetry serve many purposes. Various government education policy documents mentioned earlier, and the development document tagged Vision 2016, favor the teaching of literature as a component of the English language. Again, it is indicated in the junior secondary English language syllabus (Republic of Botswana, 2008) that the syllabus embraces two integrated components, language and literature, which are seen to be complementary. It is believed that the integration of literature with language will help learners reinforce their knowledge and use of the English language.

Furthermore, some of the specific aims of the ten-year basic education program which relate to the teaching of literature in Botswana schools include the following:

- Acquire knowledge and understanding of society, appreciation of culture including languages, traditions, songs, ceremonies, customs, social norms and a sense of citizenship.

- Acquire a good knowledge and practice of moral standards.

- Develop their own special interests, talents and skills, whether these are dexterity, physical strength, intellectual ability, and/or artistic gifts.

- Develop critical thinking and problem solving ability. (Republic of Botswana, 2002: iii)

For example, the values of the appreciation of language, culture, traditions, songs, moral standards in family and community life, developing intellectual and other talents, critical thinking and problem solving abilities are core values that the teaching of literature inculcates. As an example, literature books such as Things Fall Apart, The Amaryllis, The Play of Goggle Eyes, and anthologies in The Rain Song recommended as texts at the junior secondary level in Botswana illustrate stories, poems and plays that emphasize personal, moral and social values of traditional and contemporary African and global issues. The activities inherent in the teaching of the subject are capable of teaching values clarification and enhancing communication and language development of students in English. Also, the intellectual skills involved will enable students to comprehend language in other content areas of the school curriculum.

Finally, the identified national and educational objectives outlined in this discussion cannot be achieved without addressing the challenges that both teachers 
and students encounter in the teaching and learning process that impacts negatively on students' performance in English literature. To this end, this study attempts to elucidate the challenges that may hinder effective pedagogy in the subject and proffer some measures for improvement.

\section{Problem Statement}

It is established that literature teaching and learning at the junior secondary level is helpful to students in the language learning process. This is because of the personal involvement it fosters in readers, and the rich context it provides for the language learning process. It is also believed that literature teaching and learning enables students to gain familiarity with many features of the written and spoken language, especially in the second language (L2) learning (Republic of Botswana, 2008) context for the promotion of literacy. Also of importance is one of the pillars of Vision 2016, which articulates that Batswana (the people of Botswana) will be "educated and informed by the year 2016." The hindrance to achieving this and other educational and social goals of Botswana is the poor performance of students in literature at the junior secondary level.

Again, the 2004 Junior Certificate (Republic of Botswana, 2004) examiner's report notes in some sections that a considerable number of students did not understand some questions in the English literature paper before rushing to answer them and thereby, lost points. Furthermore, the 2008 JC report observes that some candidates were ill prepared for the Literature Paper 3 which required students to:

- Explain

- Describe

- Show feelings

- Express opinions

- Demonstrate understanding of literary aspects. (Republic of Botswana, 2008)

Furthermore, the experience of this author as a teacher at the junior secondary level for about one and a half decades, persistent student difficulties with the subject, coupled with the noted dissatisfaction of teachers with the teaching of literature, informed this study. It is hoped that the findings will help to alleviate the challenges encountered by both the teachers and students in the teaching and learning of English literature.

\section{Objectives of Paper}

1. To examine the rationale for the teaching of English Literature at the junior secondary school level in Botswana;

2. To identify the challenges/problems of the teaching and learning of English Literature at the junior secondary school level; and

3. To discuss the implications for teacher practices and strategies. 


\section{Rationale for Teaching English Literature in Botswana Schools}

The seven pillars of the famous government document Vision 2016 (Republic of Botswana, 1997) states that by the year 2016, Botswana would become:

- An educated and informed nation;

- A prosperous, productive and innovative nation;

- A compassionate, just and caring nation;

- A safe and secure nation;

- An open, democratic and accountable nation;

- A moral and tolerant nation; and

- A united and proud nation. (Republic of Botswana, 1997)

The seven pillars of Vision 2016 above are value-laden and intimately relate to moral and intellectual education. For citizens of Botswana to be well educated, and informed, compassionate, just, caring, moral and tolerant, the teaching and learning of literature both in Setswana (the national language) and English (the official language) must undoubtedly be part of the curriculum. This is because the teaching of literature has the identified academic and value-laden objectives that can contribute to the realization of the country's visionary goals. This view is further supported by DeRouche and Williams (2001) who articulate:

The two major purposes of school are cognitive-academic development and character education. Together they prepare students for the world of work, for lifelong learning, and for citizenship. (p. 8)

Furthermore, it is recognized that both academic and moral development is a great challenge for all people. It is not a surprise that Gibbons in one of the Forewords in Brooks (2001) asked some questions: "what do we, as a society, want of young people as they walk across the stage and receive their diplomas...? What do we want them to walk away with and be able to do?" He answers:

Yes, we want them to be able to write, calculate, and read, but we also want them to resolve conflicts in a peaceful manner, care about what happens to others, exercise self-discipline, show respect for others, be honest and truthful, and have confidence in themselves and others. The list of characteristics goes on and on. In short, we want to help students develop their character as well as their academic skills. (p. 9)

Moreover, it is believed that literature in both English and Setswana helps to establish the values of appreciating the world, developing a positive self-image, and understanding the connection between all people all over the world. There is no doubt that in the present global setting which stresses the interdependence of nations and communities, the ability to communicate effectively, build an understanding of cultures of the world, acquire new information, respond to the 
needs and demands of society and the workplace, and for peaceful coexistence, is important. Botswana equally shares all these ideals, and they are reflected in the nation's basic education and social goals. The assumption is that the goal of an educated and informed nation, in addition to other goals, can be achieved through literature education in the junior secondary schools. This paper will, however, focus on the teaching and learning of English literature in the second language (L2) context.

\section{Methodology}

Participants

Seventy (70) Form One students in two different schools and their two (2) English language teachers in the two junior secondary schools in Gaborone, the capital city of Botswana, were used as subjects of this study. The two schools as indicated were purposely chosen because of their nearness to the investigator's workplace and the convenience afforded by the two schools in data collection. The teachers had seven and eight years teaching experience respectively. They were judged to be in a position to furnish the information required by the investigator. There were thirtyfive (35) students in each of the two deliberately selected classes, making a total of seventy (70) students between the ages of thirteen and fifteen (13-15) years.

\section{Method of Data Collection}

An open-ended semistructured interview questionnaire was designed to interview the two teachers on a one-on-one basis as follows (see Appendix A):

1. What is your area of specialization?

2. How long have you been teaching English Literature?

3. What are the attitudes of your students to the teaching of the subject (literature)?

4. Do you like teaching English Literature to your students? Why?

5. What are the difficulties you experience with the teaching of the subject, starting with the major problems?

6. What do you perceive as the reasons for those problems?

7. How can the difficulties you have identified be remedied?

The seventy Form One students chosen were given questionnaires requiring them to respond to a few open-ended questions as stated below (see Appendix B):

a) Class:

b) Age:

c) Male or Female

1. I like studying English Literature because of these reasons:

2. I do not like studying English Literature because of these reasons:

3. List what you think are the problems you have with the learning of English Literature:

The method of data collection was very simple. Each of the two teachers helped to distribute the questionnaires. The two teachers were interviewed orally. 
The study was done with the students during their literature learning period of forty minutes in each of the two schools on different days of the week. The teachers were interviewed on their free afternoon in the week of the study.

In reporting the responses of the teachers and the students, simple qualitative and quantitative descriptions were employed. This was to ensure a greater degree of reliability and validity. It is believed that there are advantages in the multimethod approach, as it attempts to explain more fully the richness and complexity of human behavior by studying it from more than one view point; that is, by making use of both quantitative and qualitative data (Cohen, Manion and Morrison, 2005). The challenges faced by the teachers and students were as reported below.

\section{Analysis of Data}

The interviews with the teachers were done over a period of one hour each and tape-recorded in addition to notes taken during the interview. The responses were coded and examined for recurrent themes/categories. The recurrent themes were identified for discussion.

\section{Findings (Interview with Teachers)}

The two teachers interviewed, A and B, held post-graduate degrees in education and have seven and eight years of teaching experience respectively, as stated earlier. Even though the two teachers said that they enjoyed teaching literature, they went on to express reservations.

In the one-on-one discussions with the teachers during the interview, they identified the following challenges in order of importance:

1. The negative attitudes of students/general lack of interest;

2. Problems of reading, comprehension and writing in English (this is common to the majority of students);

3. Students' inability to comprehend what they read. Even though they (the students) are able to pronounce the words, they lack understanding;

4. Inadequate materials to teach as students sometimes have to share books to read;

5. Copying of written homework;

6. Content of prescribed materials/books being above or not within the students' experience;

7. Students' lack of good background in English at the primary level and having to learn literature in junior secondary school;

8. Problems of mixed ability teaching.

\section{Discussion of Findings}

Judging from various responses, the challenges faced by teachers and students in literature education might jeopardize the achievement of educational and social 
goals of literature teaching and learning in Botswana junior secondary schools. Some of the findings pertaining to teachers indicate the following:

Teacher attitude: Attitudinal issues are part of the problems facing the teaching and learning of English literature in schools. Even though the two teachers interviewed said they were not averse to teaching English literature, they adopted a defeatist tone when they said they were usually discouraged about teaching literature to their students. In the interviews with the teachers on this, some responses indicate:

- I get discouraged by students who are admitted to secondary level who have not passed well and are unable to read or respond to questions.

- Some students have difficulties with reading to start with, and to request them to read a text for interpretation becomes a problem. Where am I supposed to start from?

In addition, there are instances of negative attitudes from the teachers towards the teaching of some aspects of literature, such as poetry or drama, as they consider them boring and uninteresting. Aspects of the interview that indicate this trend are as follows:

- Students have a negative attitude towards poetry. Maybe this is a result of the approach we have been using to teach them, always asking them to identify figures of speech, which they find difficult, and students' lack of understanding.

- The low achievers and mediocre achievers would always struggle to grasp concepts with complex texts and literature genres, e.g., poetry.

Negative attitudes/vibes about teaching particular aspects of literature to students can easily be picked up by students. If teachers lack enthusiasm themselves, it is doubtful if they can help their students to develop any interest in the subject.

Students' lack of interest and negative attitudes to literature: This may be due to several factors, including those related to the teacher such as methodology/approach, difficult vocabulary/text, and lack of understanding of students' difficulties. For instance, this was picked up from students in their responses as to why they do not like studying literature:

- Literature often has difficult vocabulary

- Literature can be confusing

- Literature often has long stories and I don't understand most English words

- Literature deals with a lot of poems and I am not good at poetry

- The poetry aspect is most difficult for me

- It takes a long time to finish reading and at times I forget what the reading is about by the time I finish reading 
It is important for teachers to articulate or diagnose their students' learning problems adequately. Students' lack of interest may stem from many factors, including difficult vocabulary, difficult texts, teaching methodology, and so on. For example, one of the teachers cited lack of reading culture as a cause of students' lack of interest. What students indicated as their challenges were more than a mere inability to read as suggested by the teachers. The responses students gave suggested implications for choice of literature materials as well as methodology issues.

Students' problems of reading, comprehension and writing: Some teachers assume erroneously that the ability to read translates to literature comprehension ability. Reading is an aid and not an end to literature ability. This is further illustrated by the teacher who said that students can read out loud (pronounce/recognize) the words but are unable to comprehend. Effective literature teaching goes beyond mere reading of an interesting novel or story. Helping students comprehend literature demands that teachers be skillful at teaching it. This is because in addition to reading, students should be able to comprehend, enjoy, and respond to what they read. Finally, it is assumed that reading is an important factor that enhances writing in developing literacy skills.

Provision of resources: The allusion to the unsuitability of resources that have difficult language or contents that are far removed from the students' immediate social contexts can contribute to ineffective literature instruction. During the teacher interviews, a teacher commented that most often they are not consulted before books are recommended for students by the Ministry of Education and Skills Development (the government body that provides textbooks and other learning materials to schools). On this, a teacher comments:

- One of the problems is lack of resources such as textbooks. There is sometimes a 1-to-3 ratio in book use by students.

- I think one of the big challenges is the lack of teacher input in the book selection process for students.

In addition, it is noted that the provision of inadequate textbooks for students can be a major stumbling block to effective literature instruction.

Copying of homework: This is not a surprising development judging from the students' lack of understanding and perceptions of literature learning. If a particular subject is boring, difficult and confusing to students to start with, it is doubtful if they can do homework successfully in it. Thus, students resort to copying from one another.

Students' lack of good background in English: Several authors, such as Akyel and Yacin (1990) and Widdowson (1975), note that L2 learners find literature learning difficult because of the challenge of teaching literary texts to learners who have an inadequate background in the basic mechanics of the English language. This is evident in the teachers' complaints about the poor English background of student intakes from the primary schools. Also, Widdowson (1975) notes that the 
interpretive procedures in literature may lead the L2 learner to become confused and overloaded even at the best of times. This view probably explains some of the difficulties of the lack of understanding that the teachers noted in their students. This perception is further reinforced by a student respondent who in frustration said:

- I don't like literature because it is boring and confusing.

Mixed ability teaching: One of the teachers in this study was having difficulties with mixed ability teaching, which should not be the case. A mixed ability class should not be a challenge that would prevent teachers from effective instruction delivery. The teacher education program should prepare them to deal with such situations. Besides, presently, the average Botswana public school classroom is mixed ability in nature, and this situation informs the inclusion of mixed ability/multicultural education in the teacher preparation program of the University of Botswana. Also, this development makes it imperative for both inservice and pre-service teachers to have knowledge of mixed ability teaching.

\section{Findings (Students)}

As stated earlier, 70 students participated in this investigation. A few of them (18 or approximately 25\%) indicated that they enjoy learning literature because it is enjoyable and it involves stories that they love. However, the main focus of this paper is on the challenges faced by the majority of students (approximately 75\%), who indicated that they do not enjoy learning literature. The main themes of their responses as tallied in rank order, absolute numbers, and percentages are as follows in descending order:

1. The difficulty of understanding literature $-49(94 \%)$;

2. Difficult vocabulary - $39(75 \%)$;

3. Literature has difficult poetry aspects $-36(69 \%)$;

4. Too lengthy stories/novels, which make them lose sight of what the story was about by the time they finished reading it -34 (65\%);

5. It is boring and confusing- $32(62 \%)$;

6. Too much note taking - 26 (50\%);

7. English literature is difficult to pass, as they usually get very poor grades in tests and examinations - 21 (40\%); and

8. Requires too much thinking, which some of them find difficult to do - 14 (30\%)

\section{Discussion of Findings (Students)}

Difficulty in understanding: Some of the findings tend to indicate generally that the learners find literature difficult. Forty-nine students representing $94 \%$ of the fiftytwo (52) students having difficulty with literature cited difficulty in understanding English literature. This agrees with the views of such authors as Akyel and Yacin (1990) and Widdowson (1975), who note that L2 learners find literature learning difficult. On the same issue, another challenge to students is the difficulty in teaching creative use of language by teachers who are themselves L2 speakers of the 
language (Adeyemi, 2008) and as a result might have proficiency problems themselves. Furthermore, from the previous observations and experience of this writer, some teachers who dislike some aspects of literature such as poetry and drama usually are selective in the aspects they teach or where they are taught, and they unconsciously infect their students with the negative attitudes they unwittingly display. Thus, many of the students complained about the learning of poetry:

- I don't like literature because it uses unfamiliar words, especially in poems

- I hate poetry because the language is difficult to understand

- Literature is hard and has many poems that I don't understand.

Difficult vocabulary: According to thirty-nine students or seventy-five percent of them, unsuitable English literature books that have difficult language contribute to students' lack of interest as well as failure in the subject. This was evident by the students' frustration at learning literature because according to them, English literature is difficult to understand and has difficult vocabulary. Unfamiliar settings and cultural differences in some literature materials compound the difficulties students experience.

Difficult poetry aspects: Some teachers tend to be selective in teaching aspects of literature they enjoy, such as stories and novels, and shy away from those they consider challenging, such as poetry and other creative aspects of the English language. This probably explains the peculiar problems the students were having. Thirty-six students or sixty-nine percent of them alluded to this challenge. In addition, there are instances of general observations that many teachers skip some aspects of literature teaching such as poetry or drama because it is boring and uninteresting to them. Adeyemi (2008) notes that creative aspects of L2 language learning has been accorded very little importance both at the primary and secondary levels, which has negatively impacted students' reading and writing skills development.

Too lengthy stories/novels: Thirty-four or sixty-five percent of the students have problems with the length of their stories and novels. This situation is closely related to the use of unsuitable materials in the teaching of literature. Material selection and use should consider students' reading level, interest, familiar/authentic contents and appropriate teaching strategies. Materials should not be too lengthy or inadequate for students; otherwise they lose sight of the plot or the whole essence of the reading exercise.

Boring and confusing literature: Twenty-four students or forty-six percent said they find literature boring and confusing. This view of the learning of literature by students may be closely related to the teaching methodologies adopted by teachers. This may indicate a need for teachers to vary their approaches and methodologies for teaching the subject. There are very many interesting ways of teaching literature so that it includes activities that integrate language skills with other personal response activities such as role-play, debates, discussions, group/pair work and other problem solving and interpretive techniques in learning. 
Too much note taking: This can be explained as a fall out from teacher strategies, as twenty-six or fifty percent of the students consider it as a challenge to their learning. The teaching of literature should involve the use of varying strategies and approaches to reflect the new thinking in literature education which integrates language skills and reader-response strategies to minimize note- taking and enhance understanding and personal response in literature, as already alluded to earlier.

Literature is difficult to pass: Another complaint by twenty-one or forty percent of the students indicates that literature is difficult to pass on tests and examinations. The complaint that literature is difficult to pass as a result of poor grades in traditional tests and examinations may be linked to students' reading comprehension and writing skills. A possible reason may also be linked to unsuitable teaching resources as well as poor teaching strategies. Some of the remedies already indicated for teaching strategies and improved resources for teaching the subject can also help to improve learning.

English literature requires too much thinking: Fourteen or thirty percent of the students have problems with critical thinking skills that literature learning involves. This situation may be related to the poor English language background of the students, reflected in poor reading and comprehension skills, poor speaking and writing skills, and materials that are above the students' level of understanding. This also calls for appropriate diagnosis/understanding of students' learning difficulties in order for teachers to remediate them. Diagnosis and remediation of reading disabilities in students is an important area that needs to be addressed by teachers at the onset of the course. In the present order, much is taken for granted. There is no indication of reading diagnosis being done to screen students to determine their reading levels or readiness for the type of skill needed to tackle the learning of English literature at the junior level. Teachers just take it for granted that all students are at the same level, without due consideration of students' interests and abilities. This is a wholesale approach in teaching that needs to be reviewed in the Botswana public education system.

In view of the challenges faced by teachers and students in the teaching and learning of English literature at the junior secondary level in Botswana, the following implications are discussed.

\section{Implications for Teacher Practices and Strategies}

Some of the implications for in-service and pre-service education of teachers in connection with literature teaching are discussed below.

Exposure to approaches and strategies for teaching literature: There is a need for teacher educators to expose teachers to the different approaches available to enhance the teaching of literature taking into consideration the particular needs of their students. New orientations in literature teaching and learning involve the application of transactional theories (Karolides, 1997; Cadorath \& Harris, 1998) and integrated approaches (Carter \& Nash, 1990). 
These views to literature teaching and learning are informed by the consideration of the role of the readers, acknowledgement of the readers' prior knowledge in the reading act, and the readers' ability to interact with the text in creating meaning, and not just the writers' interpretation or meaning alone. The integrated approach theories submit that particular needs of the students concerned can be factored into the strategies to address language needs as well as individual response mechanisms. I support both views, considering L2 language learning difficulties as well as the enabling environment provided by the response strategies.

Mixed ability teaching skills: Many teachers are having difficulties meeting the needs of the diverse students in their classrooms. Even experienced teachers discover that they may not be adequately prepared to teach their students (Rassol and Curtis, 2004). This is because of the continuing challenges teachers are often confronted with in day-to-day classroom situations such as problems of students' backgrounds, multiethnic orientations, cultural backgrounds, language backgrounds, students with special needs, and so on. The education of teachers must include multicultural teaching to ensure effectiveness of teachers in the mixed ability classrooms.

Courses on materials development and evaluation: This should be an important course in teacher education. It is important in language teaching as well as in other content areas, as it would enable student teachers as well as practicing teachers to function effectively in their roles of providing and recommending useful and relevant resources for teaching literature and other subjects. When teachers are called in to help review and recommend resources for instruction, they should be empowered to do this to solve the problems of resource materials development and procurement.

Strategies for teaching literature: Strategies for teaching literature are many and varied and should include any of the three characteristics believed to be important in teaching L2 learners: that language learning be integrated (Snow and Brinton, 1988); that students be given access to problem-solving and critical thinking activities in non-threatening, cooperative contexts to foster higher order thinking (Moll \& Diaz, 1987) which include critical thinking strategies; and that learning activities be mediated or scaffolded so as to build background and promote learning (Rasool \& Curtis, 2004).

\section{Conclusion}

As students are prepared for living in the twenty-first century, it is important to help them learn the strategies and skills that will let them function effectively in all aspects of their lives. This calls for the use of effective strategies that will enhance learning and help students develop effective skills and abilities needed for the individuals to become more critical and effective communicators, as well as functional citizens of their communities and the world. Perhaps the most important factor in guiding learners to read, enjoy and learn from literature is the teacher's own attitude. If teachers show interest, read widely, and are enthusiastic about 
literature, they will communicate their own enjoyment to many of their learners. In addition, teachers must be willing to take chances and plan interactive activities that will personally involve learners. They must also be accommodating of students' responses to literature in diverse ways in order to motivate and appreciate their students' contributions in the learning process and thereby help to achieve the educational and social goals of teaching literature in the schools in Botswana and elsewhere with similar challenges.

\section{References}

Adeyemi, D. A. (2008). Approaches to teaching English composition writing at junior secondary schools in Botswana. Unpublished doctoral dissertation, University of South Africa, Pretoria.

Achebe, C. (2002). Things fall apart. Oxford: Macmillan.

Akyel, A., \& Yalcin, E. (1990). Literature in the EFL class: a study of goal-achievement incongruence. ELT Journal, 44(3), 174-180.

Brooks, D. L. (2001). Readings and activities for character education. Peterborough, NH: Cobblestone.

Cadorath, J., \& Harris, S. (1998). Unplanned classroom language and teacher training. ELT Journal, 52(3), 188.

Carter, R., \& Nash, W. (1990). Seeing through language. Oxford: Blackwell.

Cohen, L., Manion, L., \& Morrison, K. (2005). Research methods in education. New York: RoutledgeFalmer.

DeRoche E., \& Williams, M. (2001). Foreword. In D. L. Brooks, Readings and activities for character education. Peterborough, $\mathrm{NH}$ : Cobblestone.

Fine, A. (1995). The play of goggle eyes. Oxford: Heinemann.

Karolides, N. J. (1997). Reading process: Transactional theory in action. In N. J. Karolides (Ed.), Reader-response in elementary classrooms: Quest and discovery (pp. 3-28). Mahwah, NJ: Lawrence Erlbaum.

Moll, L. C., \& Diaz, S. (1987). Change as the goal of educational research. Anthropology and Education Quarterly, 18, 300-311.

Rasool, J. A., \& Curtis, A. C. (2004). Multicultural education in middle and secondary classrooms: Meeting the challenge of diversity and change. Belmont, CA: Thomson Wadsworth.

Republic of Botswana. (2008). Junior Certificate Examination: Principal Examiner's Report - Paper 3. Gaborone, Botswana: Government Printers.

Republic of Botswana. (2008). Three-Year Junior Secondary English Syllabus. Gaborone, Botswana: Department of Curriculum and Evaluation. 
Republic of Botswana. (2004). Junior Certificate Examination: Principal Examiner's Report - Paper 2. Gaborone, Botswana: Government Printers.

Republic of Botswana. (2002). Curriculum Blueprint: Ten Year Basic Education Programme. Gaborone, Botswana: Government Printers.

Republic of Botswana. (1997) Long Term Vision for Botswana, Vision 2001: Towards Prosperity for All. Gaborone, Botswana: Government Printers.

Republic of Botswana. (1994). Revised National Policy on Education (RNPE). Gaborone, Botswana: Government Printers.

Republic of Botswana. (1977). National Policy on Education. Gaborone, Botswana: Government Printer.

Snow, M. A., \& Brinton, D. M. (1988). Content-based language instruction: Investigating the effectiveness of the adjunct model. TESOL Quarterly, 22, 553-574.

Widdowson, H. (1975). Stylistics and the teaching of literature. London: Longman.

\section{Appendix A}

1. What is your area of specialization?

2. How long have you been teaching English Literature?

3. What are the attitudes of your students to the teaching of the subject (literature)?

4. Do you like teaching English Literature to your students? Why?

5. What are the difficulties you experience with the teaching of the subject starting with the major problems?

6. What do you perceive as the reasons for those problems?

7. How can the difficulties you have identified be remedied?

\section{Appendix B}

a) Class:

b) Age:

c) Male or Female

1. I like studying English Literature because of these reasons:

2. I do not like studying English Literature because of these reasons:

3. List what you think are the problems you have with the learning of English Literature: 